\title{
End-Group Evaluation of HEMA Initiated Poly( $\varepsilon$-caprolactone) Macromonomers via Enzymatic Ring-Opening Polymerization
}

\author{
N. Ugur Kaya ${ }^{1}$ and Y. Avcibasi Guvenilir ${ }^{2}$ \\ ${ }^{1}$ Polymer Science \& Technology Department, Graduate School of Science Engineering \& Technology, Istanbul Technical University, \\ Maslak, 34469 Istanbul, Turkey \\ ${ }^{2}$ Chemical Engineering Department, Faculty of Chemical \& Metallurgical Engineering, Istanbul Technical University, Maslak, \\ 34469 Istanbul, Turkey
}

Correspondence should be addressed to N. Ugur Kaya; kayana@itu.edu.tr

Received 29 December 2014; Accepted 18 March 2015

Academic Editor: Ana Figueiras

Copyright (C) 2015 N. U. Kaya and Y. A. Guvenilir. This is an open access article distributed under the Creative Commons Attribution License, which permits unrestricted use, distribution, and reproduction in any medium, provided the original work is properly cited.

\begin{abstract}
Poly( $\varepsilon$-caprolactone) (PCL) macromonomers comprising acrylate end-functionality were synthesized via enzymatic ring-opening polymerization (eROP) by utilizing commercially available Candida antarctica Lipase B (CALB), Novozyme-435. 2-Hydroxyethyl methacrylate (HEMA) was purposed to be the nucleophilic initiator in eROP. The side reactions generated due to the cleavage of ester bonds in HEMA and the growing polymer chains were investigated through altering polymerization period, initiator concentration, temperature, and enzyme concentration. ${ }^{1} \mathrm{H}$ NMR evaluations showed that minimum quantities of side reactions were in lower temperatures, initiator concentration, enzyme concentration, and lower monomer conversions. Gel permeation chromatography (GPC) results revealed that lower polydispersity along with number-average molecular weight of end-functionalized PCL macromonomers was obtained depending on higher initiator/monomer ratios, lower temperature $\left(60^{\circ} \mathrm{C}\right)$, enzyme concentration $(100 \mathrm{mg})$, and/or polymerization time $(2 \mathrm{~h})$. Furthermore, $0.1 \mathrm{HEMA} / \varepsilon$-caprolactone $(\mathrm{CL})$ ratio had higher molecular weight than $0.5 \mathrm{HEMA} / \mathrm{CL}$ ratio, while keeping a close value of methacrylate transfer, total methacrylate end-groups, and lower polyester transfer.
\end{abstract}

\section{Introduction}

Polyesters have crucial applications on medical scopes such as tissue engineering and controlled release drug carriers with their intrinsic biocompatible, biodegradable, and nontoxic nature [1]. In targeted drug delivery systems, PCL has been attracting interest as being one of the pioneering biopolyesters. Various drugs such as cisplatin, doxorubicin, and gentamicin sulfate were managed to be absorbed inside PCL chains [2]. As indicated by Williams et al. [3], PCL might also have application in tissue engineering with its bioresorbable characteristics for bone and cartilage repair as scaffold. HEMA end-functionalized macromonomers can be used in free-radical acrylic polymerization for the synthesis of comb-like and grafted polymer structures which can be used in drug delivery systems. The $\alpha, \omega$-methacrylated PCL macromonomers can alternatively be used in cross-linked polymer network formation where enhanced mechanical properties are desired.

eROP of lactones has drawn significant interest owing to its environmental friendly features such as dramatically lower temperature synthesis option, absence of heavy metal based catalysts, solvent-free production, lower energy consumption, recyclability, and reuse of enzymes $[4,5]$. As a unique technique in polymer synthesis, enzymatic polymerization has emerged expeditiously. The first eROP of lactones was offered by two independent groups in 1993 as Uyama and Kobayashi and Knani et al. Apart from being a green method in polymer synthesis, enzymatic polymerization also provides high catalytic activity, enantioselective, regioselective, chemoselective, and choroselective synthesis, and lower byproduct formation [6,7]. In particular, in biomedical applications, metal residues such as $\mathrm{Zn}, \mathrm{Zr}$, Al, $\mathrm{Ge}, \mathrm{Ti}, \mathrm{Mn}, \mathrm{Sb}, \mathrm{Sn}$, and $\mathrm{Bi}$ arising from the commercial 

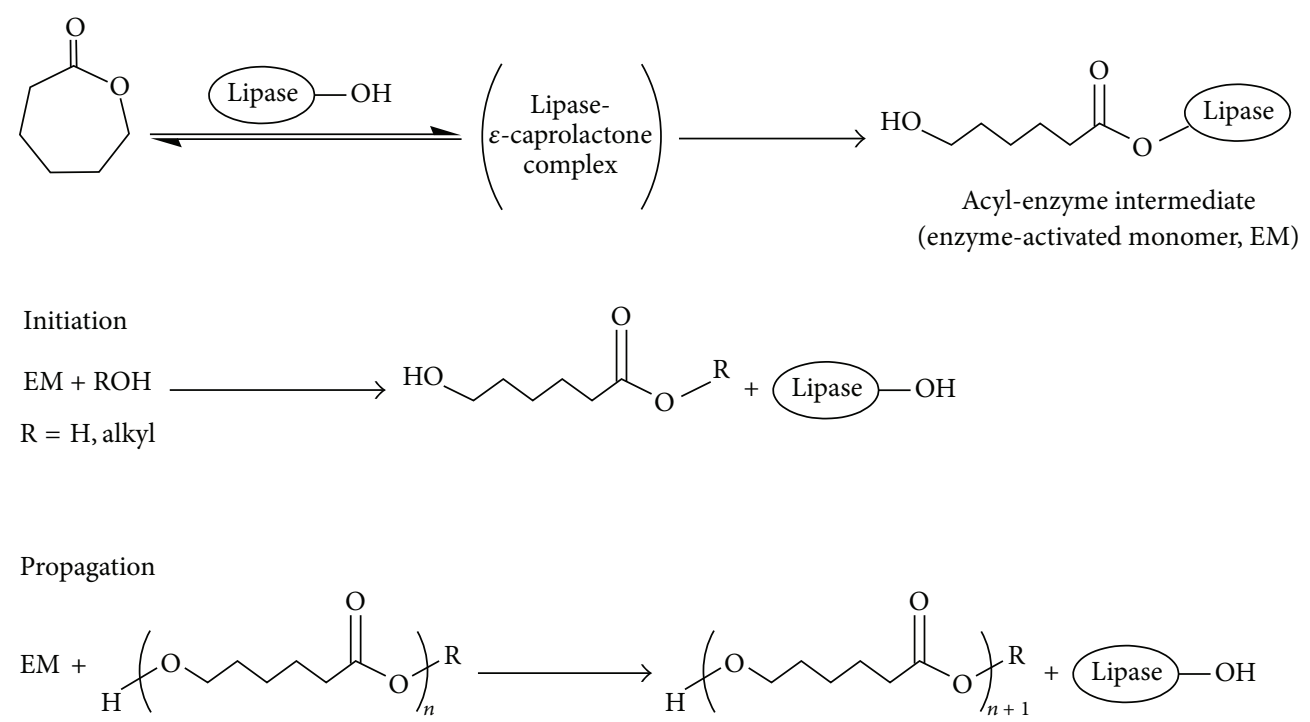

FIGURE 1: Synthesis mechanism of lipase-catalyzed eROP of CL [15].

condensation polymerization catalysts are crucial issues since organometallic catalysts are harder to be entirely removed from the final polymer which are used in vivo [8-10].

Lipase (triacylglycerol acyl hydrolase, EC 3.1.1.3) is a bond breaking enzyme catalyzing the hydrolysis of a fatty acid glycerol ester. Furthermore, lipase has an ability to induce polyester formation via in vitro bond forming in case the enzyme catalyst and adequate monomer are used together [7]. Cordova reported that CALB can efficiently catalyze the end-functionalized eROP of lactones with various ring sizes [11]. The location of the active site of CALB determines substrate specification and high selectivity maintaining a vast number of polyesters with various functional initiators and terminators $[12,13]$. The serine fragment in CALB catalyzes the enzymatic polymerization. In the first step, acyl-enzyme intermediate generates what is called enzymeactivated monomer (EM). Subsequently, nucleophilic component attacks the acyl carbon of EM. This stage is called the initiation reaction constituting a $\omega$-hydroxycarboxylic acid $(n=1)$ as the precursor of the propagation step. Water, alcohol, or any hydroxyl bearing component is a candidate as the nucleophilic initiator. During propagation, the hydroxyl end-functionality on the propagation chain attacks the EM thus adding a monomer unit to the propagating polymer (Figure 1) [14]. In eROP of lactones via lipase, the ratedetermining step is the lactone-lipase complex $[14,15]$. Novozyme-435 (commercially available CALB immobilized onto acrylic resin) performs the highest activity among the various types of lipases [16].

eROP with "initiator method" enables single-step methacrylate end-functionalized polyester synthesis which is completely free from organometallic catalysts ready to be used for biomedical applications. As the nucleophilic initiator comprises a methacryloyl group, HEMA was sufficiently attached on the end of PCL chains having $\overline{M_{n}}$ between $1300 \mathrm{~g} / \mathrm{mole}$ at $60^{\circ} \mathrm{C}$ and high lipase amount $(50 \mathrm{mg}$ lipase $/ 1 \mathrm{mmole} \mathrm{CL}$ ) in $1 \mathrm{~h}$ reaction time as stated in the literature [7, 17]. Srivastava et al. [10] reported the anhydrous bulk eROP of CL as Novozyme-435 was the catalyst and HEMA was the initiating nucleophilic alcohol; next, they obtained comb and grafted polymers from the HEMA endfunctionalized macromonomers via free-radical mechanism. Enzyme amount was 5 wt \% of monomer, and the temperature was $60^{\circ} \mathrm{C}$ with various HEMA amounts. Furthermore, Takwa et al. [12] investigated HEMA initiated eROP of CL at $80^{\circ} \mathrm{C}$ for 43.8 mmole of CL, 2 different HEMA/CL ratios, $100 \mathrm{mg}$ of Novozyme-435, and various reaction times. They proposed two side reactions apart from the eROP of CL.

The side reactions arose from breaking of the ester bond comprised by HEMA end-group of the polymer. Consequently, two acyl transfer reactions were observed regarding the polyester chains. Methacrylate transfer yields 4 different end-group structures: (1,3) HEMA end-group, (2) methacrylate end-group, $(2,3)$ 1,2-ethanediol (EG) end-group, and $(1,2)$ hydroxyl end-group. Additionally, EG groups were observed along the chain through the polyester transfer reaction (Figure 3). Takwa et al. [12,18] proposed that deeper investigations are required to diminish the side reactions. One of the possible ways might be finalizing the reaction at lower conversions.

In this study, HEMA initiated eROP of CL was performed concerning the side reactions illustrated above. It was aimed at revealing the effect of enzyme concentration, temperature, initiator/monomer ratio, reaction time on the end-groups of the macromonomers, and EG formation inside the macromonomer chains.

\section{Materials and Methods}

2.1. Chemicals. HEMA ( $\geq 99 \%$ containing $\leq 50$ ppm monomethyl ether hydroquinone as inhibitor) and Novozyme435 were purchased from Sigma-Aldrich. CL (99\%) was purchased from Alfa Aesar. HEMA and CL were dried in the evaporator over molecular sieves at $50^{\circ} \mathrm{C}$ for $24 \mathrm{~h}$ before use. 
<smiles>C=C(C)C(=O)OCCCOCCCCCC(=O)OCCOC(=O)C(=C)C</smiles>

Acyl transfer to methacrylate group

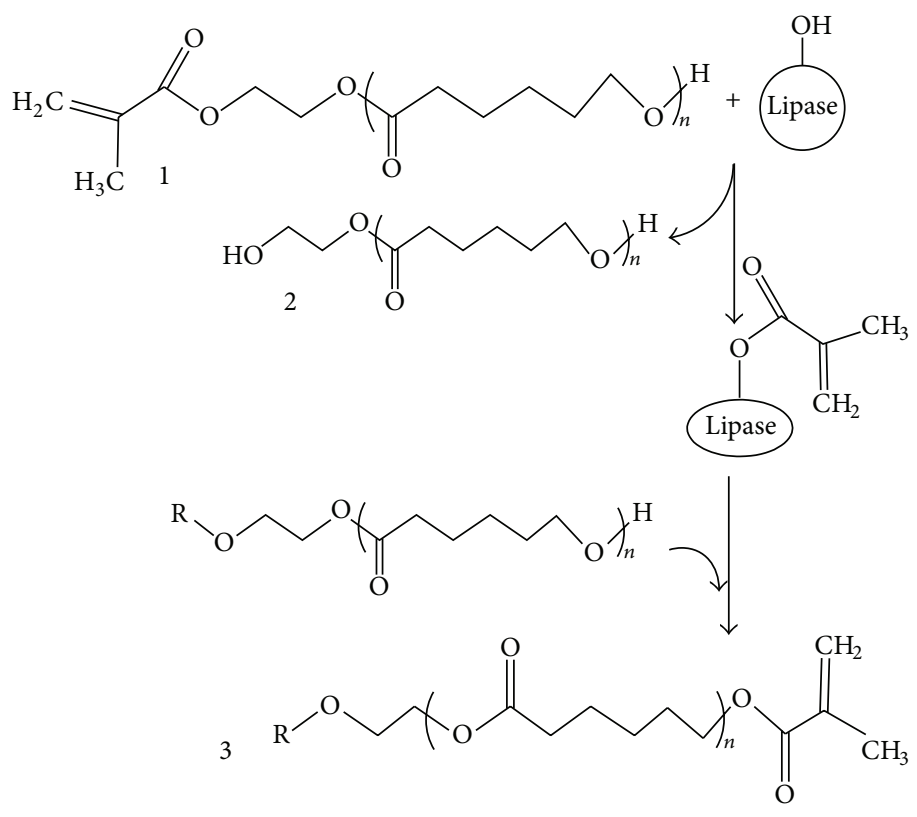

$\mathrm{R}=\mathrm{H}$ or methacrylate group
Acyl transfer of polymer chain

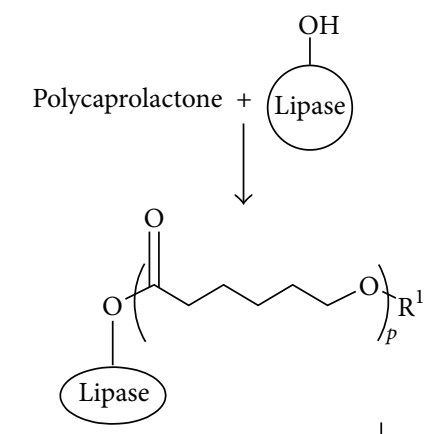<smiles>[R][C@H](C)[C@@H](C)CCCCCCC(=O)OCCO</smiles><smiles>[R10]OCCCCCC(C)OCCOC(=O)CCCCCOC=[V]</smiles>

4

$$
\begin{aligned}
& \mathrm{R}=\mathrm{H} \text { or methacrylate group } \\
& \mathrm{R}^{1}=\mathrm{H} \text { or methacrylate group }
\end{aligned}
$$

FIGURE 2: eROP of CL and side reactions thereof: methacrylate transfer (HEMA end-group of the polymer to hydroxyl end-group of polymer); 1,2-ethanediol formation inside the polyester chain $[12,18]$.

HEMA initiated eROP of CL was carried out in threenecked glass flasks under $\mathrm{N}_{2}$ atmosphere. Previously dried three-necked flasks were used in reactions capped with rubber septum in order to avoid moisture entrance. After enzyme addition, HEMA and CL were added via syringes through the rubber septum at room temperature. The reactions were terminated with chloroform addition into the reactor. Chloroform and polymer solution were filtered off the enzyme. Polymer was precipitated with excess cold methanol (MeOH) for 1 day at $-8 \pm 2^{\circ} \mathrm{C}$ at the refrigerator. To hold almost all of the polymer chains, washing procedure with $\mathrm{MeOH}$ was applied via centrifuge at $-8 \pm 1^{\circ} \mathrm{C}(2500 \mathrm{rpm}) 7$ times (each 90 minutes) in order to wash away HEMA, CL, and chloroform. Polymers washed with $\mathrm{MeOH}$ were dried at $25^{\circ} \mathrm{C}$ for 3 days.

2.2. Characterization. GPC measurements were performed with Agilent 1100 as tetrahydrofuran (THF) is the GPC solvent with $45 \mathrm{~min}$ of each measurement. The conversions (polymerization yield, \%) were calculated according to dry polymer weights. ${ }^{1} \mathrm{H}$ NMR measurements were performed with Agilent VNMRS $500 \mathrm{MHz}\left(\mathrm{CDCl}_{3}\right)$. The characteristic peaks of the structures illustrated in Figure 4 were as follows: for HEMA end-groups, h $\left(4 \mathrm{H}, \mathrm{m}, \mathrm{CH}_{2}=\right.$ $\left.\mathrm{C}\left(\mathrm{CH}_{3}\right) \mathrm{C}(\mathrm{O}) \mathrm{OCH}_{2} \mathrm{CH}_{2} \mathrm{OCH}_{2}-\right) \delta=4.31-4.38 \mathrm{ppm}$; for methacrylate end-groups, $\mathbf{m}\left(2 \mathrm{H}, \mathrm{t},-\mathrm{CH}_{2} \mathrm{CH}_{2} \mathrm{OC}(\mathrm{O}) \mathrm{C}\left(\mathrm{CH}_{3}\right)=\right.$ $\left.\mathrm{CH}_{2}\right) \delta=4.12-4.17 \mathrm{ppm}$; for CL monomers along the chains, c $\left(2 \mathrm{H}, \mathrm{t},-\mathrm{CH}_{2} \mathrm{CH}_{2} \mathrm{OCO}-\right) \delta=4.01-4.12 \mathrm{ppm}$; for EG inside the chains, e $\left(4 \mathrm{H}, \mathrm{s},-\mathrm{CH}_{2} \mathrm{C}(\mathrm{O}) \mathrm{OCH}_{2} \mathrm{CH}_{2} \mathrm{OC}(\mathrm{O}) \mathrm{CH}_{2}-\right)$ $\delta=4.27-4.30 \mathrm{ppm}$; for hydroxyl groups adjacent to ester bond of CL unit, $\mathbf{v}\left(2 \mathrm{H}, \mathrm{m}, \mathrm{HOCH}_{2} \mathrm{CH}_{2} \mathrm{OC}(\mathrm{O}) \mathrm{CH}_{2}-\right) \delta$ $=3.81-3.86 \mathrm{ppm}$; for hydroxyl groups adjacent to aliphatic methylenes of $\mathrm{CL}$ unit, $\mathbf{w}\left(2 \mathrm{H}, \mathrm{t},-\mathrm{CH}_{2} \mathrm{CH}_{2} \mathrm{OH}\right) \delta=3.62-$ $3.70 \mathrm{ppm}$; for vinylic $\mathrm{H}$ atoms of HEMA end-groups, $\mathbf{x}_{\mathbf{1}}$ and $\mathbf{y}_{1}\left(1 \mathrm{H}\right.$ each, s, $\left.\mathrm{CH}_{2}=\mathrm{C}\left(\mathrm{CH}_{3}\right) \mathrm{C}(\mathrm{O}) \mathrm{OCH}_{2} \mathrm{CH}_{2} \mathrm{O}-\right) \delta$ $=6.12-6.15 \mathrm{ppm}$ and $\delta=5.58-5.63 \mathrm{ppm}$, respectively; for vinylic $\mathrm{H}$ atoms of methacrylate end-groups, $\mathbf{x}_{2}$ and $\mathbf{y}_{2}(1 \mathrm{H}$ each, s, $\left.\mathrm{CH}_{2}=\mathrm{C}\left(\mathrm{CH}_{3}\right) \mathrm{C}(\mathrm{O}) \mathrm{OCH}_{2} \mathrm{CH}_{2}-\right) \delta=6.08-6.11 \mathrm{ppm}$ and $\delta=5.53-5.57 \mathrm{ppm}$, respectively $[12,18]$. 


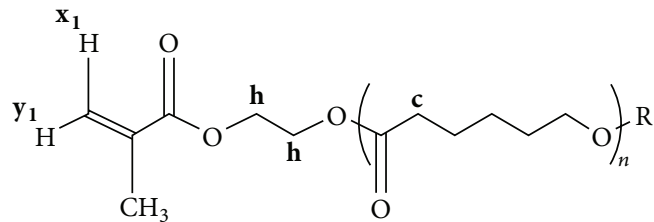<smiles></smiles><smiles>[R]OCCCCCC(C)OCCOC(C)C(=O)OCCOC([Y])(C)C</smiles><smiles>[R]OCCOC(C)C(C)OCCCCCC(C)OC(C)=O</smiles><smiles>[R][C@H](C)OC[C@H](C)OC[C@H](C)O</smiles>

$\mathrm{R}=\mathrm{H}$, or methacrylate group

$\mathrm{R}^{1}=\mathrm{H}$, methacrylate or $\mathrm{p}(\varepsilon$-caprolactone $)$ chain

Figure 3: Proposed products obtained in enzymatic ring-opening polymerization of CL as HEMA is the initiator $[12,18]$.

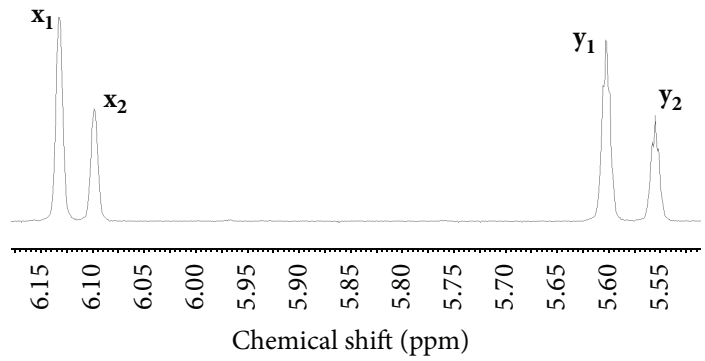

(a)

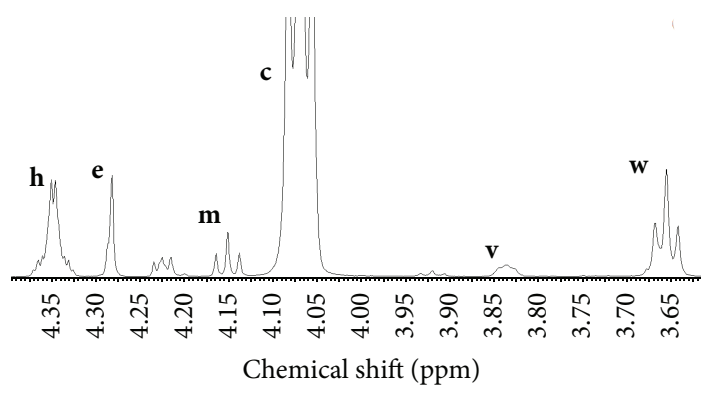

(b)

FIgURE 4: ${ }^{1} \mathrm{H}$ NMR demonstration of the dried macromonomer synthesized at $70^{\circ} \mathrm{C}, 6 \mathrm{~h}, 100 \mathrm{mg}$ Novozyme-435, $0.3 \mathrm{HEMA} / \mathrm{CL}$ (mmole/mmole), and 45 mmole CL.
The quantitative evaluation of the end-groups of macromonomers was performed using the peak areas achieved via ${ }^{1} \mathrm{H}$ NMR measurements. HEMA, methacrylate, total methacrylate, hydroxyl end-groups, and EG inside the chains were calculated as it was demonstrated in (1). In calculations, the peak areas acquired with vinylic protons of HEMA and methacrylate groups $\left(\mathbf{x}_{\mathbf{1}}\right.$ and $\mathbf{x}_{\mathbf{2}}$ or $\mathbf{y}_{\mathbf{1}}$ and $\left.\mathbf{y}_{\mathbf{2}}\right)$ had almost the same results with those demonstrated as $\mathbf{h}$ and $\mathbf{m}$ :

HEMA end-groups

$$
=\frac{(h / 4)}{((h / 4)+(m / 2)+(e / 4)+(v / 2)+(w / 2))},
$$

Methacrylate end-groups

$$
=\frac{(m / 2)}{((h / 4)+(m / 2)+(e / 4)+(v / 2)+(w / 2))},
$$

Total Methacrylate end-groups

$$
=\frac{(h / 4)+(m / 2)}{((h / 4)+(m / 2)+(e / 4)+(v / 2)+(w / 2))},
$$

Hydroxyl end-groups

$$
=\frac{(v / 2)+(w / 2)}{((h / 4)+(m / 2)+(e / 4)+(v / 2)+(w / 2))},
$$




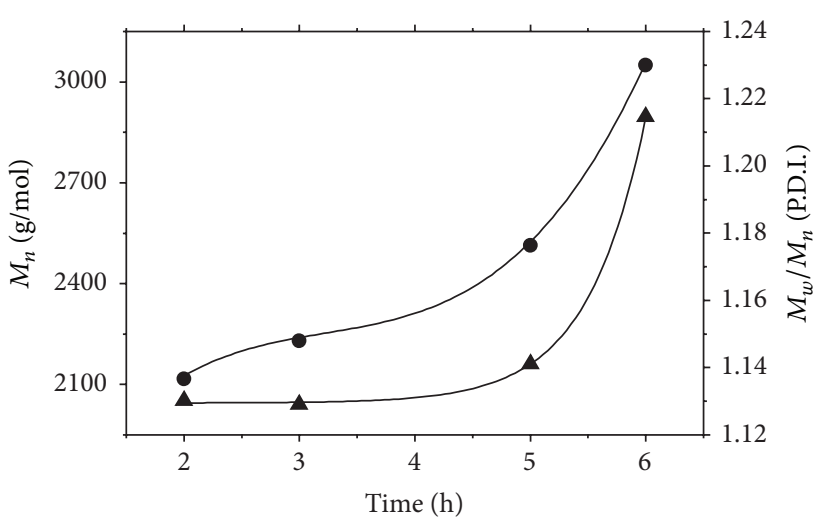

- $M_{n}$

- $M_{w} / M_{n}$ (P.D.I.)

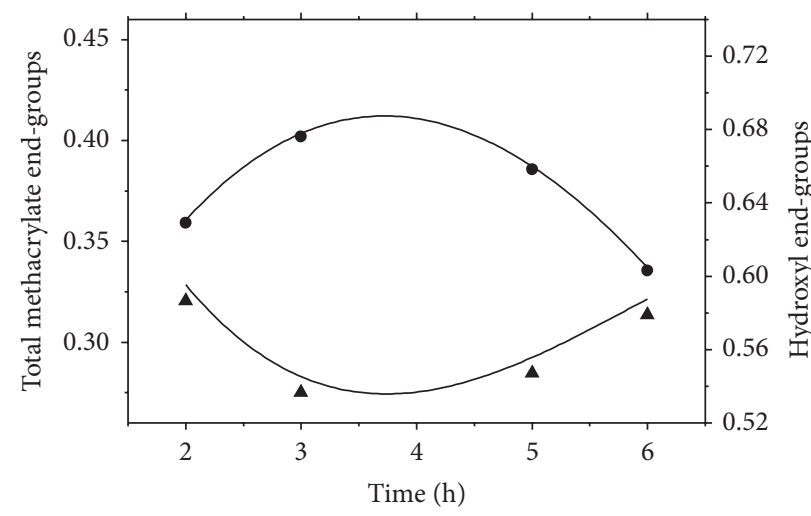

- Total methacrylate end-groups

A Hydroxyl end-groups

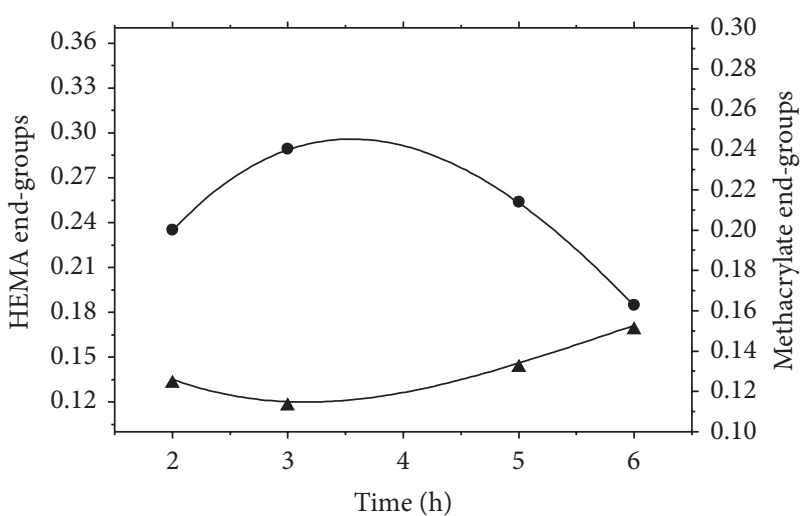

HEMA end-groups

- Methacrylate end-groups

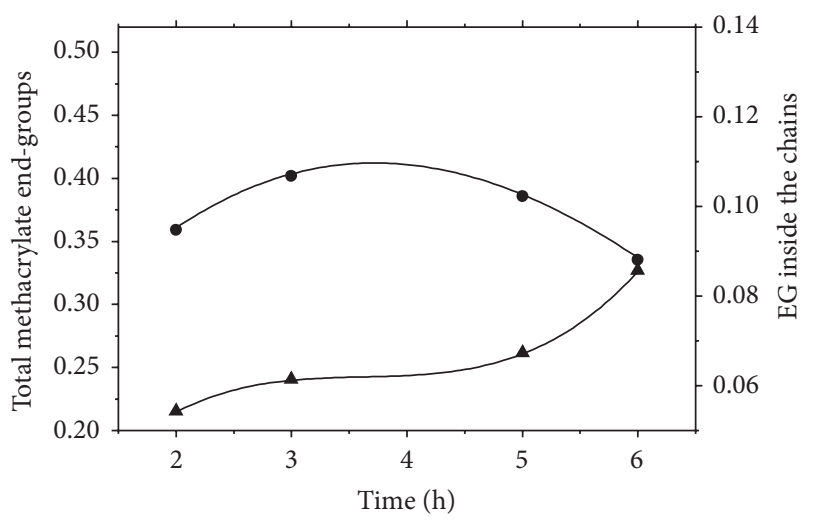

- Total methacrylate end-groups

- EG inside the chains

FIgURE 5: The effect of reaction time $(2 \mathrm{~h}, 3 \mathrm{~h}, 5 \mathrm{~h}$, and $6 \mathrm{~h})$ on $\overline{M_{n}}$, polydispersity, HEMA, methacrylate, total methacrylate, hydroxyl endgroups, and EG inside the chains (Synthesis at $70^{\circ} \mathrm{C}, 9 \mathrm{mmole} / 45 \mathrm{mmole}(0.2)$ HEMA/CL ratio, and $100 \mathrm{mg}$ Novozyme-435).

EG inside the chains

$$
=\frac{(e / 4)}{((h / 4)+(m / 2)+(e / 4)+(v / 2)+(w / 2))} .
$$

\section{Results and Discussion}

3.1. The Effect of Reaction Time. Macromonomers synthesized at $70^{\circ} \mathrm{C}, 100 \mathrm{mg}$ Novozyme-435, and $9 \mathrm{mmole} / 45 \mathrm{mmole}$ HEMA/CL ratio were obtained at 4 different reaction times $(2 \mathrm{~h}, 3 \mathrm{~h}, 5 \mathrm{~h}$, and $6 \mathrm{~h})$. Two h reaction had the lowest $\overline{M_{n}}(2116 \mathrm{~g} / \mathrm{mole})$ and $6 \mathrm{~h}$ reaction had the highest $\overline{M_{n}}$ (3049 g/mole). $\overline{M_{w}} / \overline{M_{n}}$ (Polydispersity Index, P.D.I.) raised from 1.13 to 1.21 through the reaction proceeds to $6 \mathrm{~h}$ from $2 \mathrm{~h}$ (Figure 5). The polymerization yields for the reactions were $6.6 \%, 9.4 \%, 17.7 \%$, and $21.5 \%$ for $2 \mathrm{~h}, 3 \mathrm{~h}, 5 \mathrm{~h}$, and $6 \mathrm{~h}$, respectively.

It can be seen (Figure 5) that, even at $2 \mathrm{~h}$, the macromonomers which comprise HEMA (0.235) end-groups together with remarkable amount of methacrylate end-groups (0.124) revealed that the first side reaction (methacrylate transfer) had been progressing in the early parts of polymerization. At $3 \mathrm{~h}$, there were a maximum point of HEMA end-groups (0.289) and a minimum point of the methacrylate endgroups (0.113). Next, the HEMA end-groups decreased and methacrylate transfer began increasing as the reaction proceeded. Besides, the total methacrylate end-groups showed a resembling trend with the HEMA end-groups. The hydroxyl end-groups demonstrated a minimum point between $3 \mathrm{~h}$ and $5 \mathrm{~h}$ and next increased. EG inside the chains mounted for longer reaction times indicates that the secondary side reaction became more obvious. Approximately in the first 3 hours of the reaction the HEMA addition seemed to be rising faster than methacrylate transfer. On the other hand, after 3 hours, the methacrylate transfer (the first side reaction) became more dominant than HEMA initiation of the enzyme-monomer complex (EM). Concurrently, the total methacrylate end-groups, which is the sum of HEMA and methacrylate (product of the first side reaction) end-groups, and hydroxyl end-groups had coherent trends as the endgroups might either be a methacrylate type (h and $\mathbf{m}$ ) or a hydroxyl type $(\mathbf{v}, \mathbf{w})$ (Figure 3 ). The diminishing in total methacrylates might be caused by concurrent deceleration of HEMA initiation and higher rate of reactions which ended 

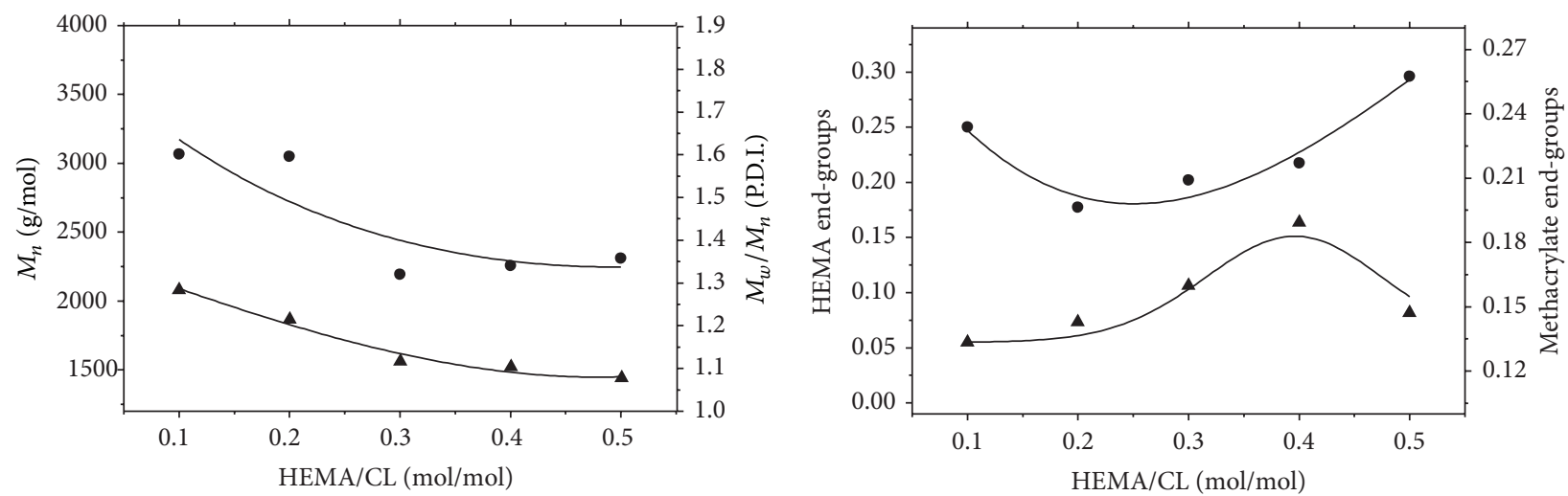
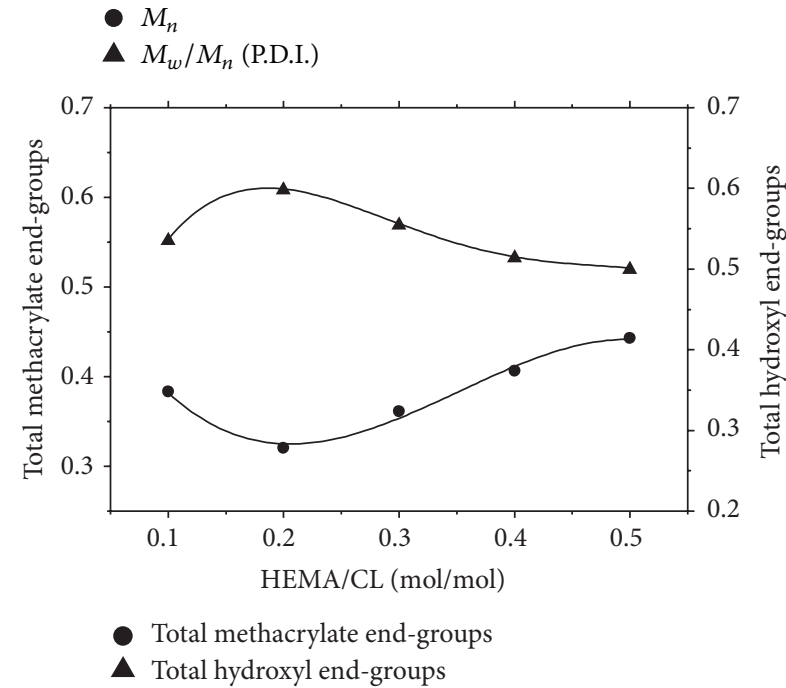

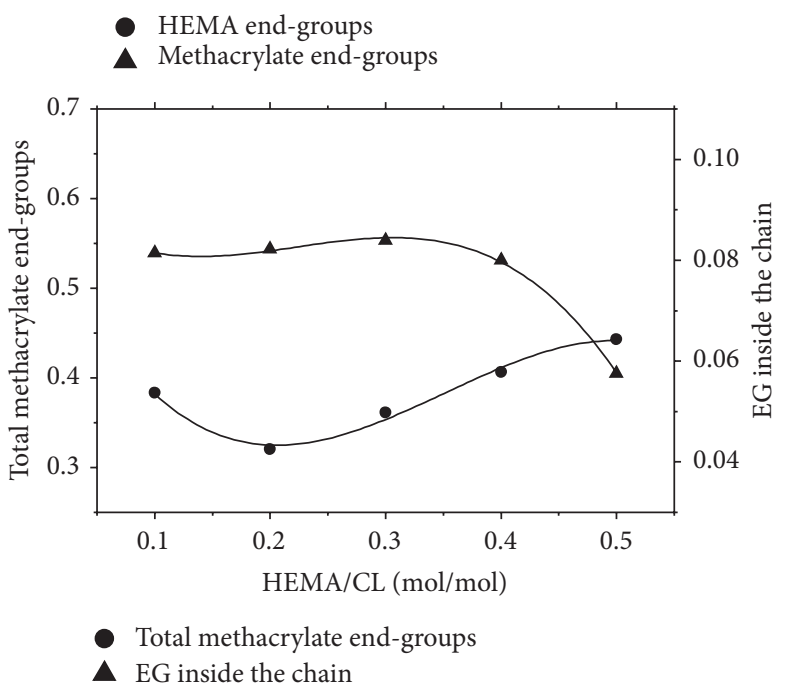

FIGURE 6: The effect of HEMA/CL on $\overline{M_{n}}$, polydispersity, HEMA, methacrylate, total methacrylate, hydroxyl end-groups, and EG inside the chains (Synthesis at $70^{\circ} \mathrm{C}, 6$ hours, $100 \mathrm{mg}$ Novozyme-435, and 9/45 (mmole/mmole) of HEMA/CL).

with hydroxyl end-groups than methacrylate end-groups during acyl transfer to methacrylate (first side reaction) (Figure 2).

3.2. The Effect of HEMA/CL Ratio. The effect of HEMA/CL ratio was investigated at two different temperatures $\left(60^{\circ} \mathrm{C}\right.$ and $70^{\circ} \mathrm{C}$ ) and two different enzyme amounts (100 mg and $200 \mathrm{mg}$ ). In Figure 6, it could be seen that the HEMA/CL ratio was altered between 0.1 and 0.5 (mmole/mmole) at $70^{\circ} \mathrm{C}$, 6 hours of reaction, and 9/45 (mmole/mmole) of HEMA/CL. $\overline{M_{n}}$ and polydispersity had a declining trend as the initiator amount increased in the medium which increased the chain number, converging the chain sizes. The polydispersity between 0.1 and $0.5 \mathrm{HEMA} / \mathrm{CL}$ ratios had values between 1.23 and 1.08. The polydispersity at 0.5 HEMA/CL ratio had a remarkable value as 1.08 which might be comparable with that of a controlled living polymerization product. On the other hand, the polymerization yield of the $0.1,0.2,0.3,0.4$, and 0.5 HEMA/CL was $27.6 \%, 21.5 \%$, $15.0 \%, 13.8 \%$, and $11.2 \%$, respectively. The dry polymer weight was descending as the HEMA/CL was increasing. This trend may be attributed to higher number of polymer chains in higher initiator/monomer ratios, since chains having lowest molecular weight (e.g., dimers, trimers) might be lost during polymer purification.

The HEMA addition performed a parabolic-like curve having closed values of 0.250 at $0.5 \mathrm{HEMA} / \mathrm{CL}$ and 0.296 at $0.1 \mathrm{HEMA} / \mathrm{CL}$. The minimum value for HEMA addition seemed to be between 0.2 and $0.3 \mathrm{HEMA} / \mathrm{CL}$ ratio. The methacrylate end-groups had a maximum at $0.4 \mathrm{HEMA} / \mathrm{CL}$ ratio. The gap between the HEMA and methacrylate endgroups had the highest value at 0.5 and lowest values at 0.4 HEMA/CL ratio. As a consistent result, the hydroxyl endgroups had a curve resembling the $x$-axis symmetry of the trend of total methacrylate end-groups. The total methacrylate end-groups had a similar trend with the HEMA endgroups representing a minimum at $0.2 \mathrm{HEMA} / \mathrm{CL}$ ratio. The EG inside the chains had no significant difference within 0.1 and 0.4 , although there was a steep decrease at $0.5 \mathrm{HEMA} / \mathrm{CL}$ ratios. This might be the result of the influence of polyester transfer that became lesser as well as the methacrylate transfer and the enzyme continued to participate in the addition of HEMA onto the PCL chains and propagation (Figure 6). The side reactions could be observed not only at the propagating polymer chains but also at the monomers. The side products might also be 1,2-ethanediol methacrylate and EG [12]. Thus, 


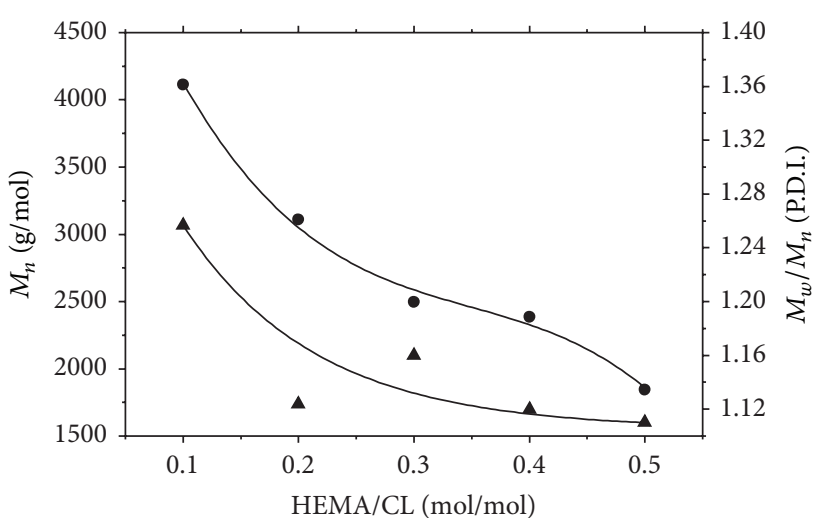

- $M_{n}$

- $M_{w} / M_{n}$ (P.D.I.)

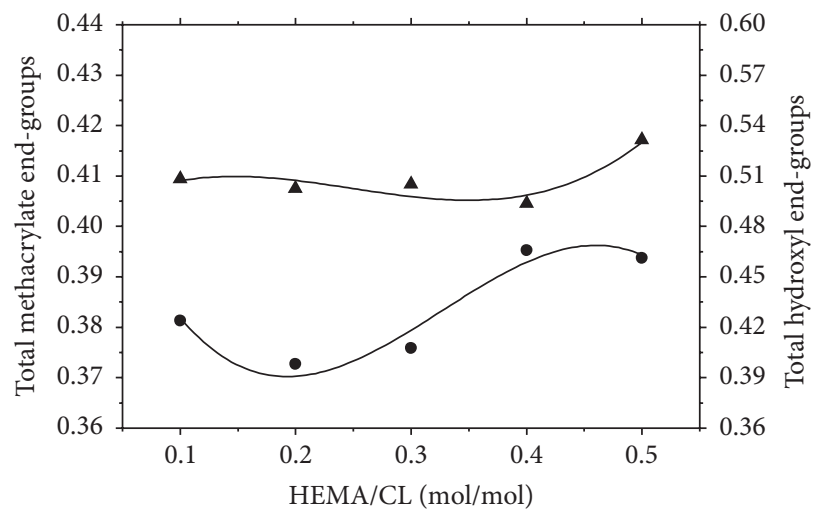

Total methacrylate end-groups

- Total hydroxyl end-groups

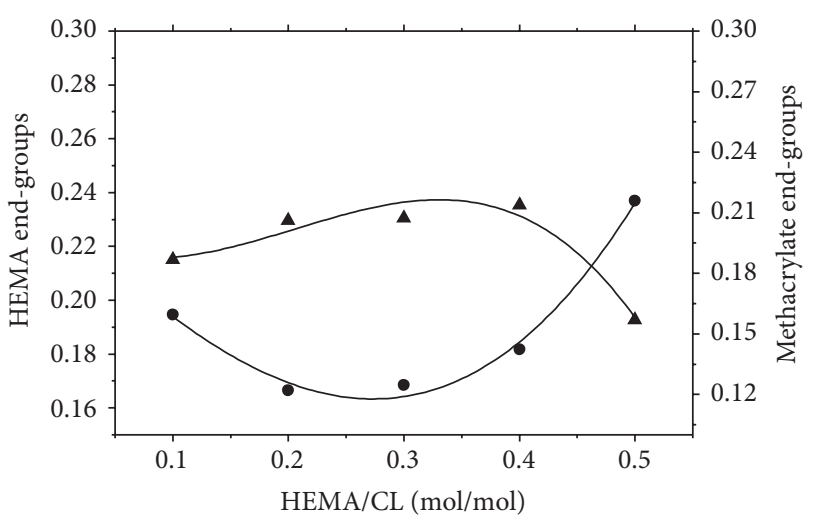

- HEMA end-groups

- Methacrylate end-groups

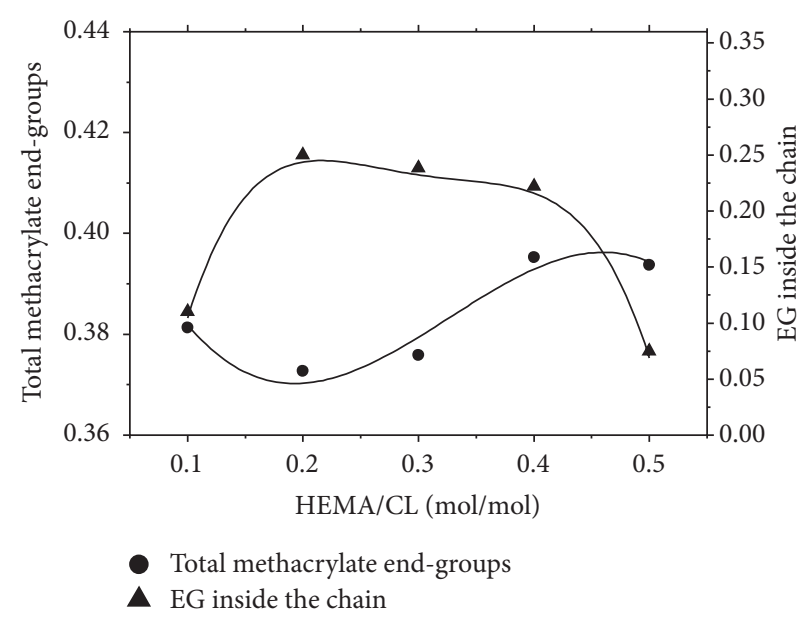

FIGURE 7: The effect of HEMA/CL on $\overline{M_{n}}$, polydispersity, HEMA, methacrylate, total methacrylate, hydroxyl end-groups, and EG inside the chains (Synthesis at 70 ${ }^{\circ}$, 6 hours, $200 \mathrm{mg}$ Novozyme-435, and 9/45 (mmole/mmole) of HEMA/CL).

at the excess amount of the ester comprising initiator, it was a possibility of the enzyme to prefer attacking the methacrylate monomer rather than the edge of the propagating chains. Consequently, it is encouraging to study at low HEMA/CL ratios or at excess HEMA amounts.

As the Novozyme- 435 amount was increased to $200 \mathrm{mg}$ from $100 \mathrm{mg}$, the other reaction parameters were kept the same $\left(70^{\circ} \mathrm{C}, 6\right.$ hours, and $9 / 45$ (mmole/mmole) of HEMA/CL). In Figure 7, $\overline{M_{n}}$ and P.D.I. were decreasing as the initiator/monomer ratio was increasing, similar to that of the $100 \mathrm{mg}$ reaction. Additionally, the $\overline{M_{n}}$ value was higher for the $200 \mathrm{mg}$ reaction, essentially the result of the increase of propagation ability at higher enzyme amount. The P.D.I. was 1.10 for $0.2 \mathrm{HEMA} / \mathrm{CL}$ ratio. Dry polymer weight of the polymers was $33.6 \%, 31.9 \%, 28.1 \%, 19.7 \%$, and $15.3 \%$ for 0.1 , $0.2,0.3,0.4$, and 0.5 of HEMA/CL, respectively. The same trend of the polymerization yield is similar to that of the reactions conducted with $100 \mathrm{mg}$ enzyme. Moreover, enzyme amount had the effect of increasing the polymerization yield.

The HEMA addition was also a parabolic-like curve having closed values of 0.237 at $0.5 \mathrm{HEMA} / \mathrm{CL}$ and 0.195 at $0.1 \mathrm{HEMA} / \mathrm{CL}$. The minimum value for HEMA addition was 0.167 at 0.2 initiator/monomer. Likewise, the methacrylate end-groups demonstrated a peak behavior between 0.2 and 0.4 initiator/lactone ratio resembling a similar trend with the inverse of the HEMA addition as the first side reaction (the methacrylate transfer) was the consequence of cleavage of the ester bond on HEMA end-group, transferring as the methacrylate end-group. The total methacrylate end-groups had no remarkable change, having the highest value of 0.373 and minimum value of 0.395 at 0.2 and 0.4 HEMA/CL ratios, respectively. In spite of the fact that there was an insignificant change in total methacrylate end-groups, the EG inside the chains had a major amount of variations as the highest value is 0.249 (0.2 HEMA/CL) and the lowest value was 0.075 (0.5 HEMA/CL). It is worth to mention that this value was 0.110 at 0.1 initiator/lactone ratio which was relatively close to the lowest value. Obviously, at 0.1 and 0.5 initiator/lactone ratios, both of the side reactions seemed to be less dominant than the other values.

\subsection{The Synergetic Effect of Temperature and Initiator/Lactone} Ratio. In Figure 8, it was demonstrated that the comparison of the influence of two different temperatures while HEMA/CL ratio changed. The enzyme amount was kept high in order to investigate the effect of parameters more 

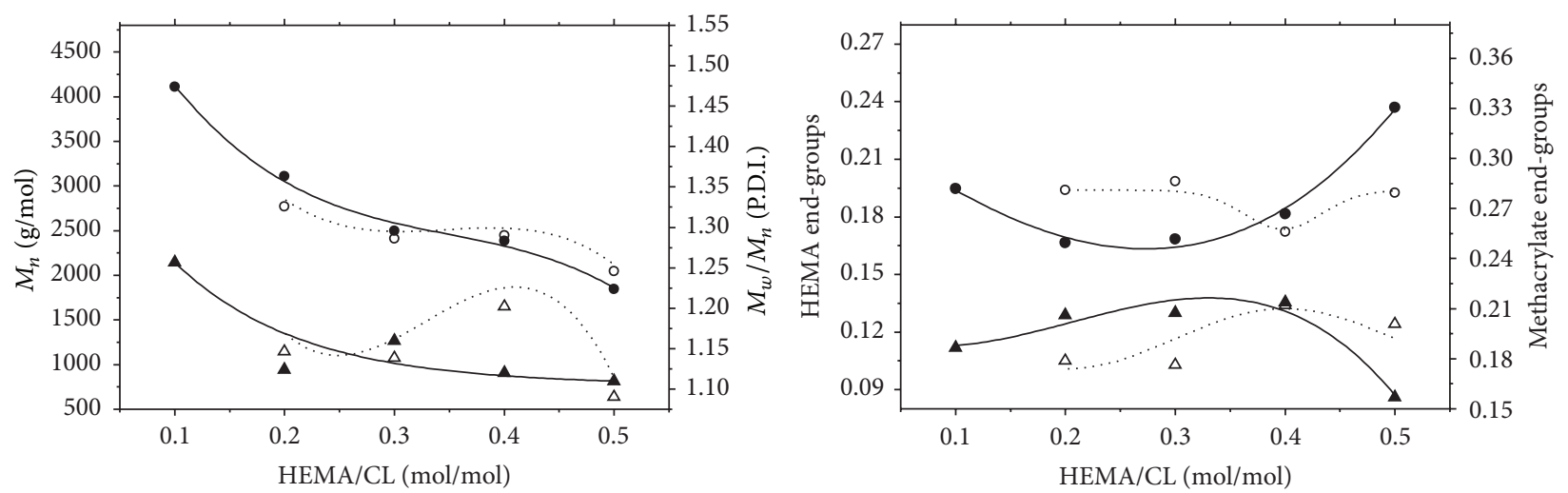

○ $M_{n}\left(60^{\circ} \mathrm{C}\right)$

- $M_{n}\left(70^{\circ} \mathrm{C}\right)$

$\triangle M_{w} / M_{n}$ (P.D.I.) $\left(60^{\circ} \mathrm{C}\right)$

- $M_{w} / M_{n}$ (P.D.I.) $\left(70^{\circ} \mathrm{C}\right)$
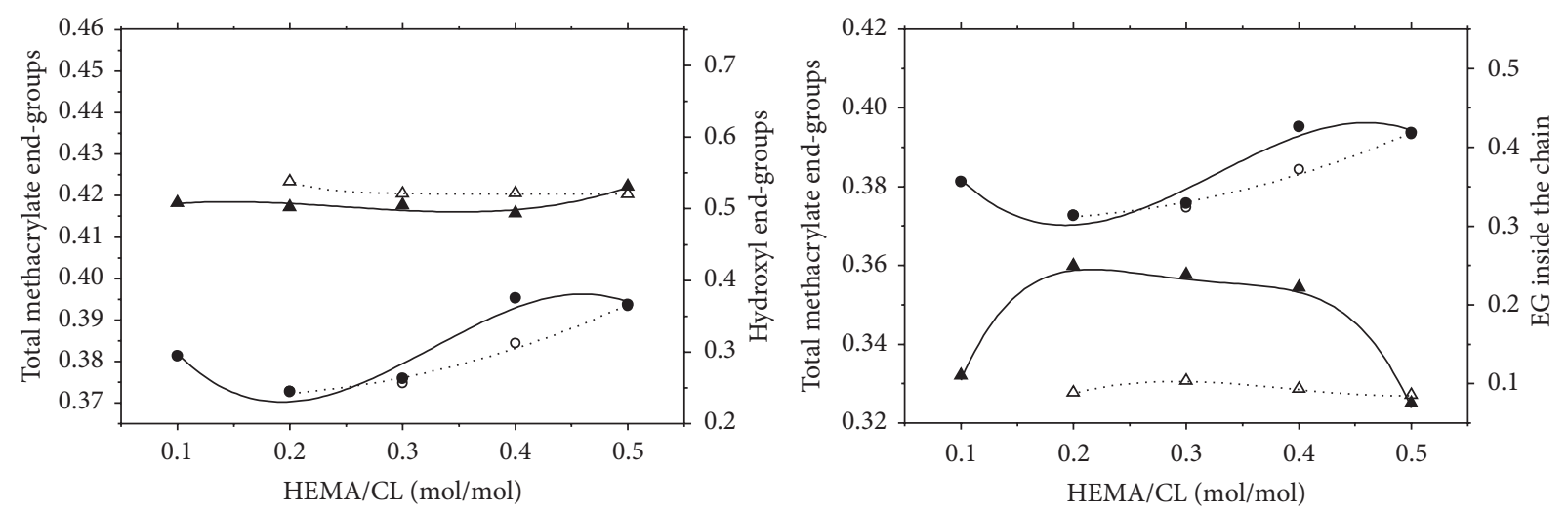

- Total methacrylate end-groups $\left(60^{\circ} \mathrm{C}\right)$

- Total methacrylate end-groups $\left(70^{\circ} \mathrm{C}\right)$

$\Delta$ Hydroxyl end-groups $\left(60^{\circ} \mathrm{C}\right)$

A Hydroxyl end-groups $\left(70^{\circ} \mathrm{C}\right)$

- HEMA end-groups $\left(60^{\circ} \mathrm{C}\right)$

- HEMA end-groups $\left(70^{\circ} \mathrm{C}\right)$

$\triangle$ Methacrylate end-groups $\left(60^{\circ} \mathrm{C}\right)$

- Methacrylate end-groups $\left(70^{\circ} \mathrm{C}\right)$

- Total methacrylate end-groups $\left(60^{\circ} \mathrm{C}\right)$

- Total methacrylate end-groups $\left(70^{\circ} \mathrm{C}\right)$

$\triangle \mathrm{EG}$ inside the chains $\left(60^{\circ} \mathrm{C}\right)$

- EG inside the chains $\left(70^{\circ} \mathrm{C}\right)$

Figure 8: The effect of HEMA/CL, at $60^{\circ} \mathrm{C}$ and $70^{\circ} \mathrm{C}$, on $\overline{M_{n}}$, polydispersity, HEMA, methacrylate, total methacrylate, hydroxyl end-groups, and EG inside the chains (Synthesis at $60^{\circ} \mathrm{C}$ versus $70^{\circ} \mathrm{C}, 6$ hours, and $200 \mathrm{mg} / 45 \mathrm{mmole}$ Novozyme-435/CL).

obviously. The $\overline{M_{n}}$ values were close together at all values of HEMA/CL ratio that resemble the P.D.I. except for the maximum point at $0.4 \mathrm{HEMA} / \mathrm{CL}$ ratio for both temperatures. Polymerization yields were calculated as $24.7 \%, 21.9 \%$, $14.6 \%$, and 11.5 for $0.5,0.4,0.3$, and $0.2 \mathrm{HEMA} / \mathrm{CL}$ ratios at the $60^{\circ} \mathrm{C}$ reactions. The polymerization yield had a diminishing trend inverse to the initiator/lactone ratio consistent with $70^{\circ} \mathrm{C}$ reactions.

For HEMA and methacrylate end-groups, the minimum point of HEMA addition and the maximum point of methacrylate end-groups were at $0.4 \mathrm{HEMA} / \mathrm{CL}$ ratio. It was noted that this convergence seemed to be apparent in between 0.2 and 0.4 (probably close to 0.3 ). Furthermore, the gaps between highest and lowest values were more significant at $70^{\circ} \mathrm{C}$ owing to higher activity of the lipase at higher temperature. In spite of this higher activity of the enzyme, the total methacrylate end-groups had a slightly higher amount between 0.2 and 0.4 and a comparable value at $0.5 \mathrm{HEMA} / \mathrm{CL}$ ratios. Moreover, while the EG inside the chains had a high alteration at $70^{\circ} \mathrm{C}$, there was a relatively lower difference of this value as the initiator/lactone increased. Thus, it might be favorable to perform the reactions at lower temperatures.

\section{Conclusions}

All of the indications revealed that Novozyme- 435 has high activity enough to catalyze EM formation, initiation, and propagation, cleaving the ester bond of the hydroxyl bearing acrylate initiator at the same time. As a conclusion, it is important to prefer lower reaction temperatures to reduce the side reactions inside the sufficient activity range of Novozyme- 435 or other lipase types. In the first two hours of reaction, approximately the same amount of HEMA was successfully introduced into macromonomers with the sixth hour of reaction; HEMA addition only increased until the third hour and tended to diminish in the following hours. Total methacrylate end-groups had also increased up to three hours, following a decrease along with reaction time. EG 
inside the chains, which is the indicator of polyester transfer, increased with time. Thus, as the reaction progressed, the first side reaction (methacrylate transfer) increased, the total methacrylate end-groups did not change remarkably or diminished, and second side reaction (polyester transfer) increased. It is obvious to finalize the eROP at low reaction times and conversions in order to obtain lower side reactions and comparable HEMA addition. Furthermore, the lower enzyme amount might be preferable in order to realise higher HEMA addition, lower methacrylate transfer, comparable total methacrylate end-groups, and minimum EG inside the chains. HEMA/CL ratio can also be chosen minimum as both of the side reactions seemed to be lower at both temperatures and enzyme amounts, still conserving the total methacrylate amount sufficient. In addition to these, higher molecular weight and polymerization yield of macromonomers can be obtained at lower initiator/lactone ratios. There might be further investigation of the effects of lower conversions, temperatures, and HEMA/CL ratios and less active lipases on the addition of HEMA onto the edge of PCL macromonomers with minimized side reactions.

\section{Conflict of Interests}

The authors declare that there is no conflict of interests regarding the publication of this paper.

\section{References}

[1] S. Kobayashi, "Lipase-catalyzed polyester synthesis-a green polymer chemistry," Proceedings of the Japan Academy Series B: Physical and Biological Sciences, vol. 86, no. 4, pp. 338-365, 2010.

[2] B. S. Wong, S.-H. Teoh, and L. Kang, "Polycaprolactone scaffold as targeted drug delivery system and cell attachment scaffold for postsurgical care of limb salvage," Drug Delivery and Translational Research, vol. 2, no. 4, pp. 272-283, 2012.

[3] J. M. Williams, A. Adewunmi, R. M. Schek et al., "Bone tissue engineering using polycaprolactone scaffolds fabricated via selective laser sintering," Biomaterials, vol. 26, no. 23, pp. 48174827, 2005.

[4] R. A. Gross, A. Kumar, and B. Kalra, "Polymer synthesis by in vitro enzyme catalysis," Chemical Reviews, vol. 101, no. 7, pp. 2097-2124, 2001.

[5] K. A. Barrera-Rivera, A. Flores-Carreón, and A. MartínezRicha, "Enzymatic ring-opening polymerization of $\varepsilon$-caprolactone by a new lipase from Yarrowia lipolytica," Journal of Applied Polymer Science, vol. 109, no. 2, pp. 708-719, 2008.

[6] Y. Yang, Y. Yu, Y. Zhang, C. Liu, W. Shi, and Q. Li, "Lipase/esterase-catalyzed ring-opening polymerization: a green polyester synthesis technique," Process Biochemistry, vol. 46, no. 10, pp. 1900-1908, 2011.

[7] S. Kobayashi, "Recent developments in lipase-catalyzed synthesis of polyesters," Macromolecular Rapid Communications, vol. 30, no. 4-5, pp. 237-266, 2009.

[8] S. Chatti, G. Behnken, D. Langanke, and H. R. Kricheldorf, "Biodegradable polyesters based on cis-1,4-butenediol," Macromolecular Chemistry and Physics, vol. 207, no. 16, pp. 1474-1484, 2006.
[9] H. R. Kricheldorf, "Syntheses of biodegradable and biocompatible polymers by means of bismuth catalysts," Chemical Reviews, vol. 109, no. 11, pp. 5579-5594, 2009.

[10] R. K. Srivastava, K. Kumar, I. K. Varma, and A.-C. Albertsson, "Chemo-enzymatic synthesis of comb polymers," European Polymer Journal, vol. 43, no. 3, pp. 808-817, 2007.

[11] A. Córdova, "Synthesis of amphiphilic poly( $\varepsilon$-caprolactone) macromonomers by lipase catalysis," Biomacromolecules, vol. 2, no. 4, pp. 1347-1351, 2001.

[12] M. Takwa, Y. Xiao, N. Simpson et al., "Lipase catalyzed HEMA initiated ring-opening polymerization: in situ formation of mixed polyester methacrylates by transesterification," Biomacromolecules, vol. 9, no. 2, pp. 704-710, 2008.

[13] A.-C. Albertsson and R. K. Srivastava, "Recent developments in enzyme-catalyzed ring-opening polymerization," Advanced Drug Delivery Reviews, vol. 60, no. 9, pp. 1077-1093, 2008.

[14] H. Uyama and S. Kobayashi, "Enzyme-catalyzed polymerization to functional polymers," Journal of Molecular Catalysis B: Enzymatic, vol. 19-20, pp. 117-127, 2002.

[15] C. Jérôme and P. Lecomte, "Recent advances in the synthesis of aliphatic polyesters by ring-opening polymerization," Advanced Drug Delivery Reviews, vol. 60, no. 9, pp. 1056-1076, 2008.

[16] G. Sivalingam and G. Madras, "Modeling of lipase catalyzed ring-opening polymerization of $\varepsilon$-caprolactone," Biomacromolecules, vol. 5, no. 2, pp. 603-609, 2004.

[17] H. Uyama, S. Suda, and S. Kobayashi, "Enzymatic synthesis of terminal-functionalized polyesters by initiator method," Acta Polymerica, vol. 49, no. 12, pp. 700-703, 1998.

[18] Y. Xiao, M. Takwa, K. Hult, C. E. Koning, A. Heise, and M. Martinelle, "Systematic comparison of HEA and HEMA as initiators in enzymatic ring-opening polymerizations," Macromolecular Bioscience, vol. 9, no. 7, pp. 713-720, 2009. 

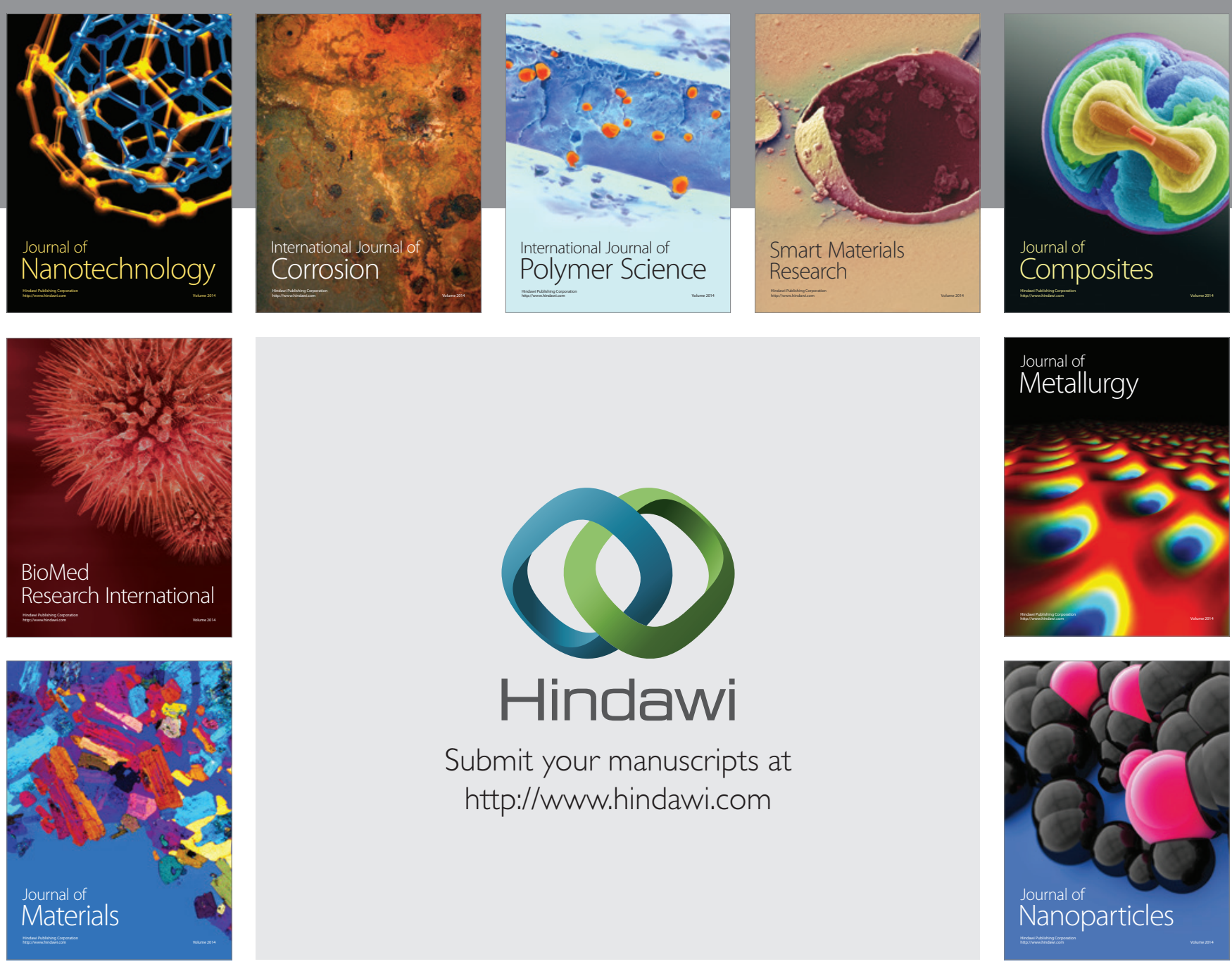

Submit your manuscripts at http://www.hindawi.com
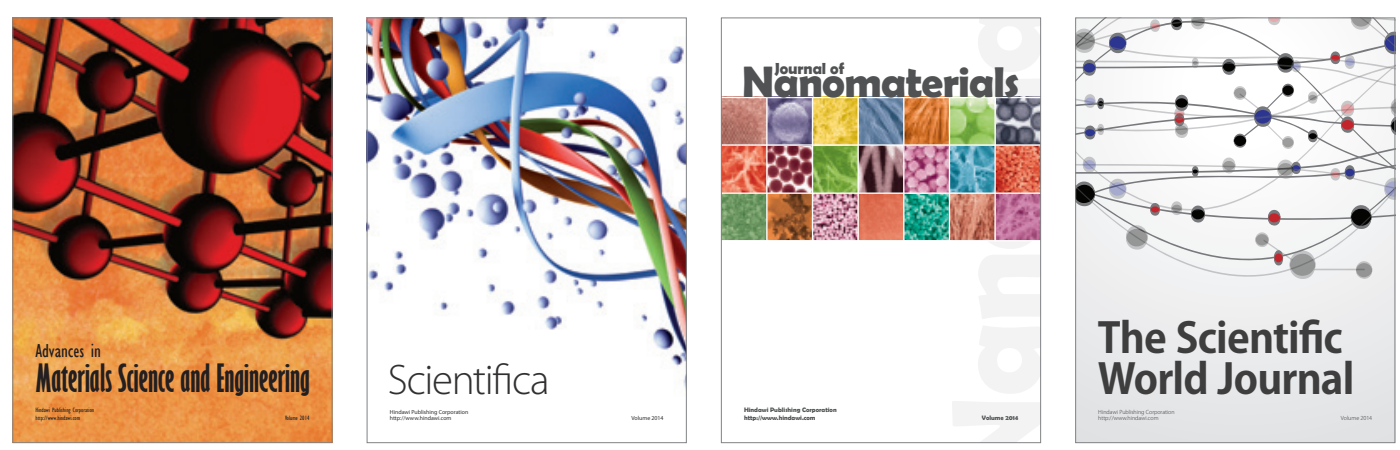

\section{The Scientific World Journal}
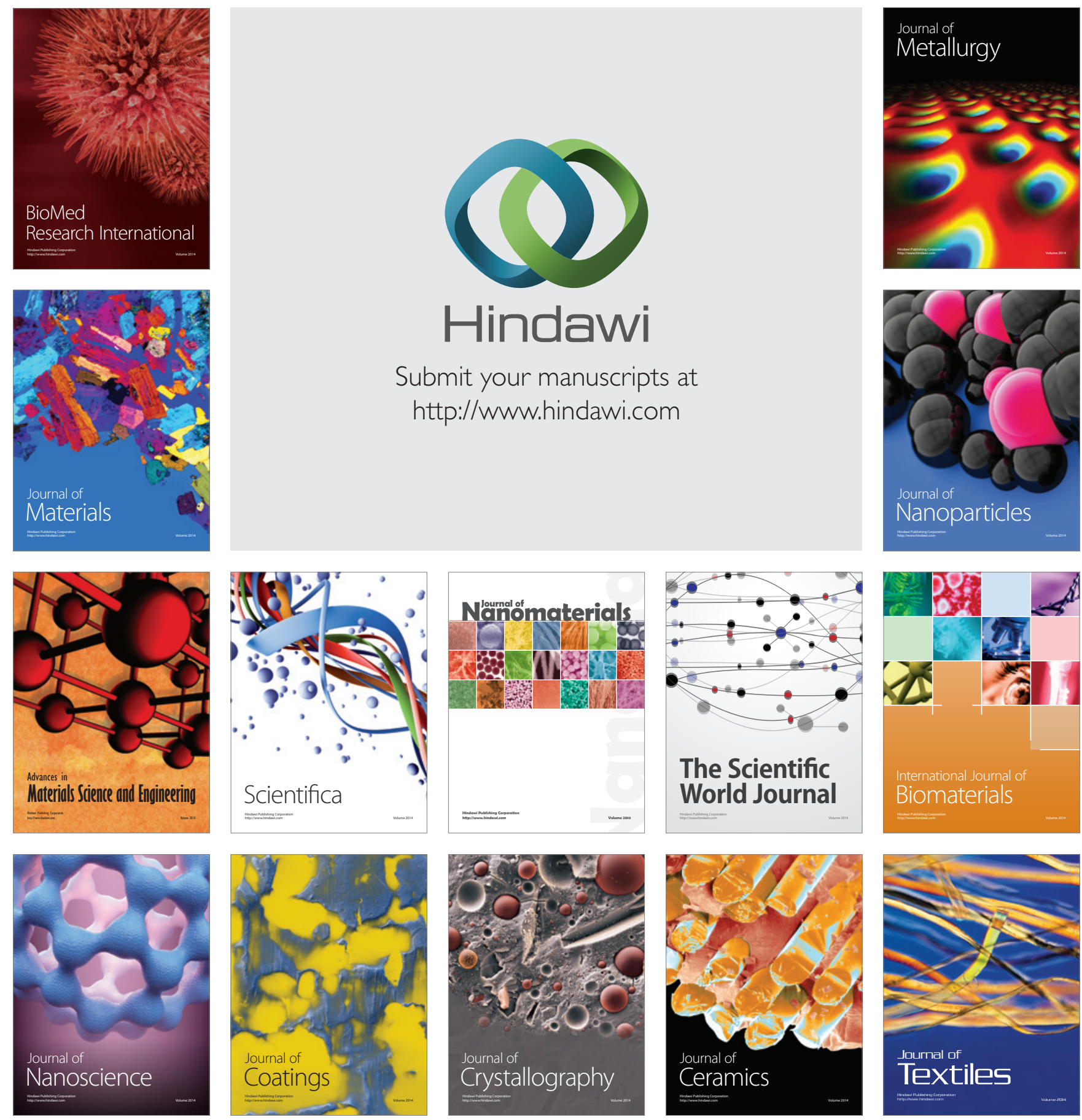